\title{
ELECTRONIC BILL PRESENTMENT AND PAYMENT
}

Legner, Christine, University of St. Gallen, Müller-Friedberg-Strasse 8, 9000 St. Gallen, Switzerland, christine.legner@unisg.ch

Wende, Kristin, University of St. Gallen, Müller-Friedberg-Strasse 8, 9000 St. Gallen, Switzerland, kristin.wende@unisg.ch

\begin{abstract}
Although various authors have postulated the benefits of Electronic Bill Presentment and Payment (EBPP), penetration of electronic invoicing is in practice still low. The following article investigates the status of European EBPP implementations in B2B relationships. Based on an empirical survey of 27 companies, it provides a state-of-the-art analysis of EBPP implementations in an industrial environment. As with other e-business scenarios, network externalities can serve as an explanation of the relatively low dissemination of EBPP. The article discusses the key decisions related to EBPP which determine network externalities: the choice of the EBPP model, the electronic channel and the invoice formats. Based on the survey results, it derives three stages of EBPP implementation characterised by specific EBPP models, channels and formats. As a conclusion, the existence of hubto-hub connections between EBPP consolidators is regarded as a major success factor for the future penetration of EBPP.
\end{abstract}

Keywords: EBPP, Financial Supply Chain, electronic invoicing, B2B collaboration. 


\section{MOTIVATION - THE EBPP DISCREPANCY}

Improving the interorganisational flow of information promises significant potentials in terms of reduced process costs and cycle times as well as increased customer satisfaction and revenues. Electronic linkages between suppliers and customers have proven to be successful in supply chain processes, but are much less frequent in financial processes. With regard to invoicing, Electronic Bill Presentment and Payment (EBPP) received substantial attention in the $\mathrm{B} 2 \mathrm{C}$ environment in the late 1990s (Horan 1998, NACHA 2001). At the same time, the first EBPP service providers such as PayNet in Switzerland emerged.

When it comes to business-to-business relationships, various authors (NACHA 2001, Fairchild 2004, Pfaff, Skiera and Weiss 2004a, Tanner and Koch 2004) have discussed the benefits of electronic invoicing compared to paper-based invoicing. These include the argument that invoice issuers can achieve direct cost savings on paper, printing and postage. They can streamline their processes through the automatic allocation of invoices to payments, improve cash flow management and accelerate the revenue cycle through earlier customer payments, due to faster invoice delivery and faster dispute resolution (reducing days sales outstanding). These savings are complemented by a number of less tangible benefits, including enhanced customer service and increased customer satisfaction. The receivers of such invoices benefit from eliminating media conversion, data entries and thereby errors, the possibility to use cash discounts increasingly due to shorter process cycle times and increased process efficiency through eliminating manual data entries, automatically matching purchase orders to invoices, invoice reconciliation and account assignment. These savings are estimated at around 10 CHF per invoice for invoice issuers and 100 CHF for invoice receivers (Tanner et al. 2004) or up to 90\% of the overall invoice processing costs (Pfaff, Skiera and Weitzel 2004b).

Despite the obvious savings potential, the penetration of electronic invoicing is in practice still low. The reasons are manifold - the unwillingness of partners to cooperate on this electronic basis, a lack of, restrictive or impeding legislation, or the problem of choosing the right solution are just a few examples. This low penetration can be explained by "excess inertia" or "start-up problems" typical of e-business scenarios in which positive network externalities prevail (Katz and Shapiro 1985, Stabell and Fjeldstad 1998, Gowrisankaran and Stavins 2004, Buxmann, Wüstner and Kunze 2005). The value for members within a network would increase with every new member joining, but too many standards and diverse technical solutions prevent potential members from taking the disproportionate risk of deciding on a specific implementation (Weitzel and König 2003). The existence of direct and indirect network effects also holds true for EBPP since companies typically base their EBPP implementation decision on the number of business partners they can reach with electronic invoicing and the availability, experience and size of EBPP service providers.

The following article therefore investigates the status of European EBPP implementations in a business-to-business environment. Based on an empirical survey of 27 industrial companies, it provides a state-of-the-art analysis of EBPP implementation. The research focuses on the key decisions determining positive network externalities:

- To what extent has EBPP penetrated European industrial companies?

- Which of the postulated EBPP models are currently in use? Is there a convergence towards either one of the models or a specific consolidator?

- Which electronic channels and standardised message formats are used for interacting with business partners?

This article is structured as follows: Section 2 summarises basic concepts and previous research on EBPP, and positions it within Financial Chain Management. The following section explains the background of the survey and the main results with respect to EBPP dissemination, EBPP models, integration with business partners and implementation challenges. Chapter 4 concludes with the main 
findings related to network externalities in EBPP. It derives various EBPP implementation stages characterised by different EBPP models and electronic channels.

\section{ELECTRONIC BILL PRESENTMENT AND PAYMENT (EBPP)}

\subsection{EBPP and the Financial Chain}

Since the late 1990s, the emerging possibilities of the Internet have led to the idea of replacing paperbased by electronic invoices (NACHA 2000, Segev and Gebauer 2000, Young 2000, Epper-Hoffmann 2001, Gamble 2001, Alt and Zbornik 2002). The concept of Electronic Bill Presentment and Payment (EBPP) goes beyond electronic invoicing, i.e. transferring the invoice from issuer to receiver using an electronic channel (bill presentment). It includes the electronic payment of the invoice (bill payment) as well as transferring payment data to the issuer (bill posting).

Recently, Pfaff, Skiera and Weitzel (2004b) have postulated that financial processes - in contrast with traditional supply chain processes - still lack professional management. They developed the concept of the Financial Chain (or Financial Supply Chain) for identifying potential improvements in financial processes and distinguish trade enablement, covering all processes prior to product or service delivery (qualification, sourcing, pricing, hedging), and trade settlement, referring to the processes thereafter (invoice issuing, complaints, payment) (Pfaff et al. 2004b). With reference to the concept of the Financial Chain, EBPP can be assigned to trade settlement. Complaints about incorrect invoices are not directly covered by EBPP, but exert a large impact on the costs of paper-based processes and days sales outstanding (DSO). A recent survey among the top 1000 German companies (excluding financial institutions and insurance companies) indicates that the greatest optimisation potential is to be found in the trade settlement phase, especially in invoice issuing (Skiera \& König \& Gensler \& Weitzel \& Beimborn \& Blumenberg \& Franke \& Pfaff 2004).

In addition to the term EBPP, EIPP (Electronic Invoice Presentment and Payment), IBPP (Internet Bill Presentment and Payment) (Eicker and Schwichtenberg 2002) or OBP (Online Billing and Payment) (Dickerson \& Raby \& Sittinger \& Stewart 2004) are used in the literature. Whereas IBPP and OBP merely imply usage of the Internet as a medium for electronic invoice transfer, EIPP relates to electronic invoice processing in the business-to-business (B2B) area. In some publications, EBPP denotes more specifically business-to-consumer (B2C) aspects (NACHA 2001, PayStream Advisors 2002, Dickerson et al. 2004). However, as the term EBPP seems to have prevailed, it is used in this paper as an umbrella term for all types of electronic invoicing, regardless of the electronic medium and the target group.

\section{$2.2 \quad$ EBPP Models}

The EBPP literature (NACHA 2001, Alt et al. 2002, Pfaff et al. 2004a) distinguishes between two different EBPP models: the Direct Model and the Consolidator Model. The Direct Model is characterised by a bilateral exchange of invoices between issuer and receiver, which can either have the form of a Seller Direct or a Buyer Direct Model (NACHA 2001). The Seller Direct Model implies that the vendor possesses the EBPP system on which invoices are presented to customers (one-tomany relationship). In the Buyer Direct Model, the customer controls the EBPP application (many-toone relationship). The vendor either posts his invoices on the customer's system or the customer creates the invoice himself from his own order (self-billing).

In order to promote many-to-many relationships between sellers and buyers, the Consolidator Model was established in the late 1990s. In the Consolidator Model, a service provider (consolidator or bill consolidator) provides the EBPP application. "A consolidator acts as an intermediary, collecting or aggregating invoices from multiple sellers for multiple buyers, eliminating the need for point-to-point connections.” (NACHA 2001, p. 11). Besides collecting and presenting invoices, the major task for 
consolidators consists in converting different data formats from sellers to the preferred data formats of customers. Another important service is that of transferring invoices in accordance with existing law, by guaranteeing secure data transfer and providing invoices with electronic signatures. Usually, the consolidator offers additional functionality to invoice issuer and invoice receiver, such as financial services (e.g. factoring, insurance, credit ratings, payment processes, dunning, encashment), workflow protocols and analysis tools, archiving, accounts payable (AP) and accounts receivable (AR) system integration and dispute management (NACHA 2001, Tanner et al. 2004). These additional tasks can be performed by Biller Service Providers (BSP) and Customer Service Providers (CSP) (Fairchild 2002, Tanner et al. 2004). However, the roles of BSPs and CSPs are about to merge with that of consolidators.

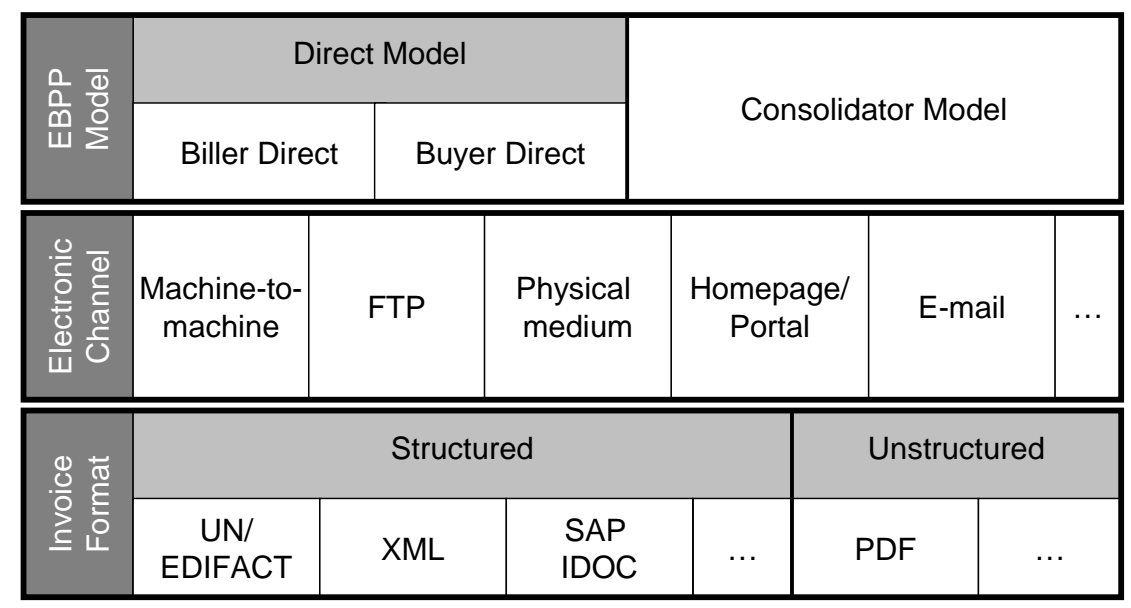

Figure 1. $\quad$ EBPP implementation alternatives

In addition to the choice of the EBPP model, several alternatives are available for implementing the exchange of electronic invoices (see Figure 1). This applies to the electronic channel as well as to the invoice format. With regard to the electronic channel, either a machine-to-machine connection can be established using EDI or the Internet, or invoices can be presented on the issuer's homepage or portal for download (Tanner et al. 2004). Other possibilities include FTP, e-mail or even physical media like $\mathrm{CD}$ or disc. Ideally, invoice information is exchanged using a machine-readable (structured) data format, which can be a proprietary ERP system export (e.g. SAP IDOC), a "neutral" or standard format such as UN/EDIFACT, or an XML industry standard. In recent years, specific invoice standards have also been developed, such as swissDIGIN in Switzerland (Tanner and Wölfle 2005), Finvoice in Finland (based on the European ePI standard) or Isabel e-Invoice in Belgium. These standards give recommendations on the invoice content, specify obligatory and optional fields within an invoice, and some also define the data format (e.g. UN/EDIFACT, XML).

\section{STATE OF THE ART OF EBPP PENETRATION}

\subsection{Background to the survey}

In order to assess the readiness and acceptance of EBPP in B2B relationships, the authors conducted an EBPP survey in August and September 2005. The survey focused on chemical companies and their business partners. The chemical industry can be characterised by the need "to be competitive and cut costs, expand revenues, and improve customer service while simultaneously dealing with lagging demand, overcapacity, and declining margins. Meanwhile, their customers are becoming more empowered and demanding, and wanting lower prices, more service, and their own cost savings.” (Thayer 2002, p. 17). Chemical companies deal with a heterogeneous customer base, since they 
typically serve various industries, among them other chemical companies, but also the pharmaceutical, construction or rubber industry.

Data collection was performed in August and September 2005 using telephone interviews based on a structured questionnaire. The interview results were sent to the interviewees for their review and then evaluated by the researchers. Interviewees were from the departments involved in EBPP activities, typically in IT or e-business, but also in finance and purchasing. They have been working in EBPP implementations or projects for outgoing and/or incoming invoices and had a sound knowledge of EBPP within their company context.

\begin{tabular}{|c|c|c|c|l|c|}
\hline \multicolumn{2}{|l|}{ Employees (in thousands) } & \multicolumn{2}{l|}{ Turnover (in bn $€$ ) } & Industry & 10 \\
\hline$<5$ & 2 & $<5$ & 7 & Specialty Chemicals & 7 \\
\hline $5-10$ & 5 & $5-10$ & 9 & Base Chemicals & 3 \\
\hline $10-25$ & 8 & $10-25$ & 7 & Discrete Manufacturing & 3 \\
\hline $25-100$ & 9 & $>25$ & 4 & Consumer Products & 4 \\
\hline$>100$ & 3 & & & Others & \\
\hline
\end{tabular}

Table 1. Interview sample analysed by employees, turnover and industry $(n=27)$

The high response rate (with only 12 out of 39 companies refusing participation) indicates that EBPP is seen as a highly topical subject. Rejections were due to a lack of experience, interest or current projects in EBPP. In total, 27 interviews were conducted. Mainly large companies with more than 5 billion $€$ turnover in 2004 (average 18.8 billion $€$ ) and 41,400 employees on average participated in the survey. 17 companies came from the chemical industry, including seven base chemicals and ten specialty chemicals companies. Other companies interviewed were from pharmaceuticals, discrete manufacturing, consumer products, transport and distribution. All companies interviewed were situated in Western Europe (with a focus on Germany and Switzerland), but mostly operate worldwide. The interview partners typically answered the questionnaire for the European, only some for the worldwide EBPP activities of their company. Details about the sample are depicted in Table 1.

The focus of the survey was on factors influencing the dissemination of EBPP in practice and thereby explaining network externalities in EBPP. We concentrated on direct and indirect network externalities which depend upon the number of companies who are in the same "network". Applied to EBPP, the utility for a company largely depends on the number of business partners it can interact with using an EBPP scenario. As a consequence, the EBPP implementation - consisting of EBPP model, the electronic channels and invoice formats - has to be compatible with the EBPP implementation chosen by its business partners. Although the sample may not be representative of EBPP in general due to the size and selected industry focus of the companies, it does provide an insight into EBPP dissemination and challenges.

\subsection{Dissemination of electronic invoicing}

With respect to the current implementation status of EBPP and solutions for suppliers and customers and within the group, the large majority of companies already use EBPP. Only five companies interviewed have not yet started EBPP implementation, and only three of them have no plans to start EBPP projects. Most plan to invest (further) in EBPP solutions or have current projects within the areas in which they are not yet active. On average, around $60 \%$ of the companies have already implemented EBPP solutions with either customers, suppliers or other companies within the same group. EBPP seems to be slightly more frequent with suppliers, whereas in the case of electronic invoicing with customers, more projects are in process. 


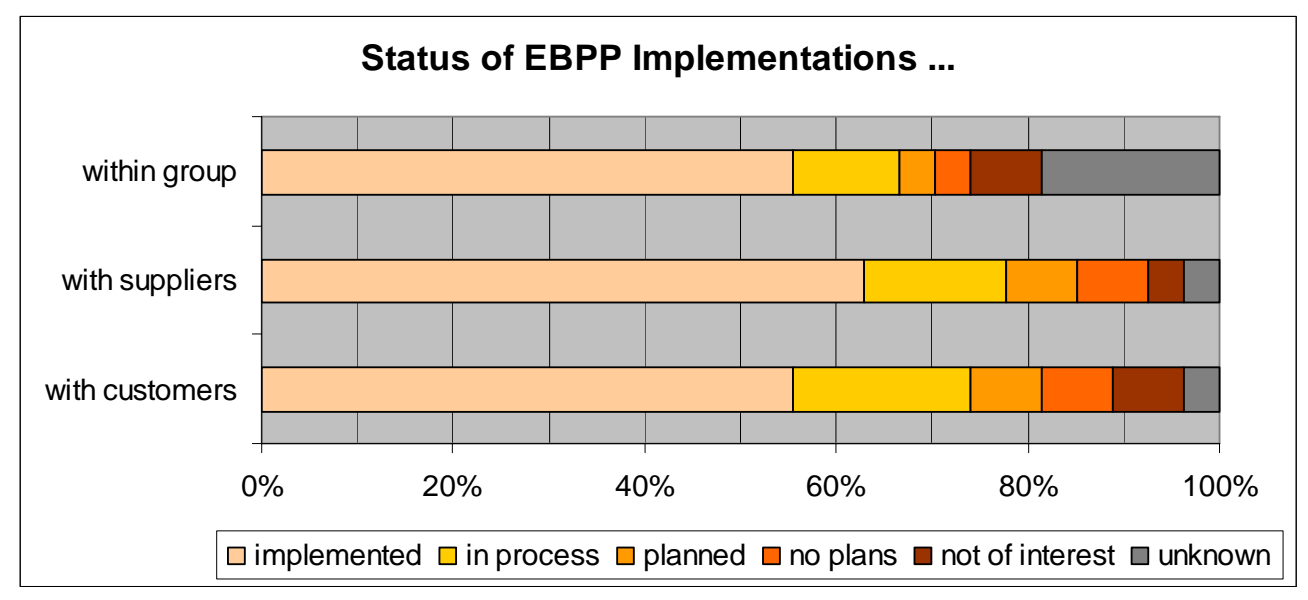

Figure 2. $\quad$ EBPP implementation status $(n=27)$

The actual percentage of invoices sent or received electronically gave a slightly different perspective to the otherwise positive picture of the implementation status (see Figure 3). With the exception of only one company receiving more than $60 \%$ of its invoices electronically and one company sending more than $60 \%$ of all invoices electronically, the majority of companies receive or send less than $10 \%$ of all invoices in electronic form. Furthermore, some companies have not completely replaced their paper-based invoices, but only send or receive electronic invoices in addition to paper-based documents. They argue that the legal requirements are still unclear to companies or cannot be met easily. This underlines the fact that EBPP dissemination is still at an early stage.
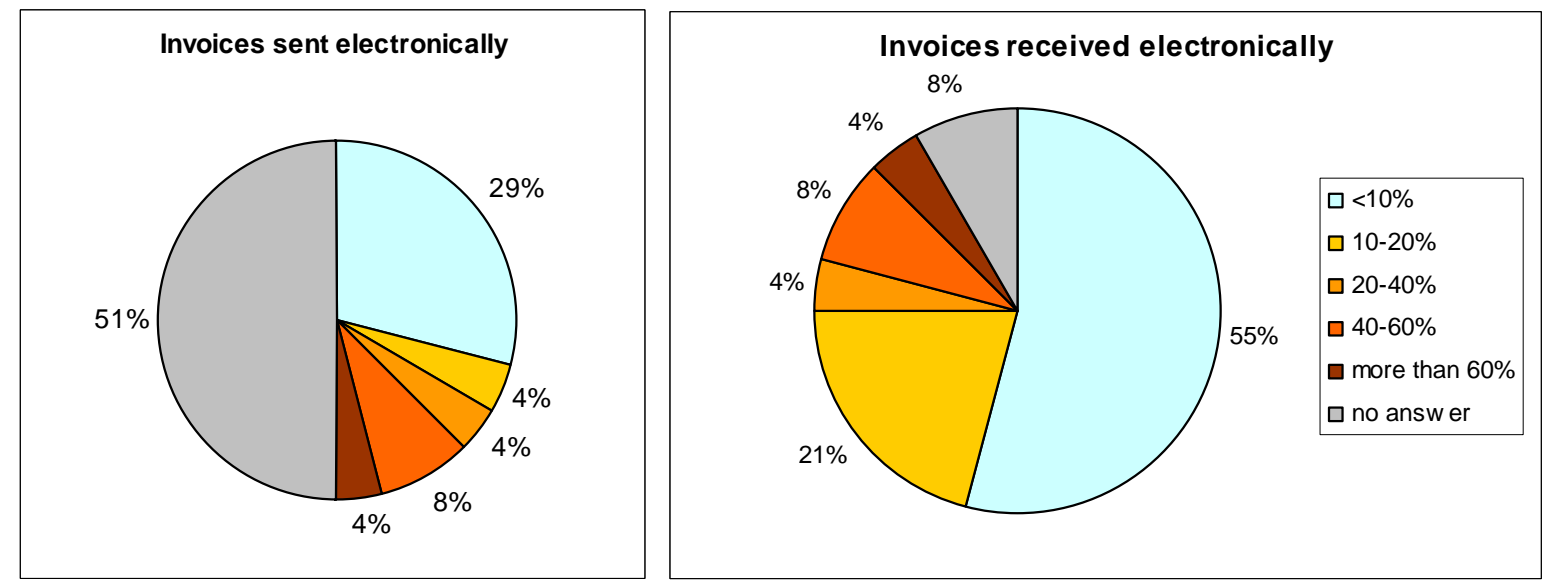

Figure 3. Invoices sent and received electronically in percentage of all invoices $(n=24)$

\subsection{EBPP models}

Although researchers have been extensively discussing the advantages and disadvantages of the different EBPP models, the survey shows no clear dominance of one of the existing models: More than $50 \%$ of the companies in the survey combine both the direct and the consolidator model. Out of the companies having only one model in place, one third use the direct model and about one sixth only consolidators. The companies using both models stated no clear preference for any particular model. As a matter of fact, the added value of EBPP consolidators is not yet clear to the companies surveyed. In addition, the survey did not reveal the emergence of any leaders in the consolidator market; most consolidators were named only once, among them Syntrade, Inovis, TietoEnator, PayNet, BillingZone, Isabel, Itella. OB10 is only used by three companies. Although there is no clear market trend towards 
one or more dominant consolidators, the results of the survey point to the relevance of industry hubs in the EBPP market. At the moment Elemica, a global industry platform in the chemical industry, simply transfers invoices between its members, without converting and aggregating them. However, Elemica has set up an e-invoicing working group and plans to extend its offering to include bill presentment functions. The survey results underline the fact that Elemica is becoming increasingly recognised as a major service provider for electronic invoicing by the chemical industry - nine companies named it as their preferred EBPP consolidator. Besides Elemcia, Trade-Ranger, an industry platform for the petrochemicals industry, is also named as EBPP consolidator.

Extending the argument that consolidators can add significant value to EBPP transactions in many-tomany relationships by offering several electronic channels and data formats, it is surprising that the direct model is still prevalent. Just four companies have started e-invoicing with consolidators only since 2004. On the one hand, this is a result of the EDI history of many large companies (Pfaff et al. 2004b) (see Section 3.4). On the other hand, network externalities in the consolidator market can provide an explanation. Companies will only choose a specific consolidator if it already has a critical mass of their own business partners using its services (Frech, Egle and Myrach 2005). Many EBPP service providers were founded during the "Internet boom", a period of rapid innovation, resulting in excess capacity (Varian, Farell and Shapiro 2004). Many companies waited for consolidation of the market to avoid the disproportionate risk of deciding prematurely in favour of a certain consolidator and running the risk of stranding in too small a network if their partner decided on another consolidator. This phenomenon is also called "awaiting aggressively" (Weitzel et al. 2003). Since then, market leaders have actually emerged in some countries (e.g. PayNet in Switzerland, Isabel in Belgium), which increases the attractiveness of consolidators, but still leaves the problem of a limited geographic scope in a B2B environment. Another factor that positively influences the emergence of consolidators is the clarification of legal requirements, such as electronic signatures. Consolidators conform with existing law, which is cost-intensive for companies to establish within their own organisations (Tanner et al. 2004).

Nevertheless, the survey revealed that the decision in favour of a certain consolidator is influenced either by the industry (e.g. TradeRanger for petrochemicals, Elemica in the chemical industry, Syntrade for wholesalers and retailers) or by the geographical focus of the company (e.g. Isabel in Belgium, PayNet in Switzerland, Itella in Northern Europe). As a result, a global company that does business in several industries must consider using several consolidators covering target regions and industries in order to reach as many business partners as possible.

\subsection{Electronic integration with business partners and data formats}

The companies in the sample support an average of more than two different electronic channels and invoice formats simultaneously. The exchange of structured invoices (directly with business partners or indirectly using consolidators and hubs) with UN/EDIFACT or XML is the preferred channel nearly all companies use this delivery option. Chemical companies often transfer e-invoices via the Elemica platform with the XML industry standard ChemXML. Unstructured PDF invoices which cannot be integrated directly into the customer's AP system are often presented on portals or sent via e-mail. SAP IDOC is used for internal company invoice delivery. Channels like FTP or physical media as well as other EDI and other software formats have low relevance (Figure 4).

Although EDI is associated with high operating costs and extensive coordination effort (Tanner et al. 2004), it is obviously less laborious to use established bilateral EDI connections for transferring invoices, which also protects existing investments in EDI solutions (Segev et al. 2000, PayStream Advisors 2002). Instead of switching to Internet technologies, companies stick with the existing EDI infrastructure and just add the special UN/EDIFACT message type for invoices ("INVOIC") (UN Economic Commission for Europe 2001) to the portfolio of UN/EDIFACT messages in use. 


\begin{tabular}{|l|r|}
\hline Invoice format / standard \\
\hline PDF & $67 \%$ \\
\hline $\begin{array}{l}\text { XML industry standard } \\
\text { (ChemXML, RosettaNet, Odette/VDA) }\end{array}$ & $50 \%$ \\
\hline UN/EDIFACT & $50 \%$ \\
\hline SAP IDOC & $50 \%$ \\
\hline Own (non XML) format & $21 \%$ \\
\hline Other EDI standard & $13 \%$ \\
\hline Own XML format & $8 \%$ \\
\hline Other software standards & $4 \%$ \\
\hline Others & $4 \%$ \\
\hline
\end{tabular}

\begin{tabular}{|l|r|r|}
\hline Electronic channel \\
\hline Machine-to-machine & 23 & $96 \%$ \\
\hline E-mail & 14 & $58 \%$ \\
\hline Portal & 12 & $50 \%$ \\
\hline FTP & 4 & $17 \%$ \\
\hline $\begin{array}{l}\text { Others } \\
\text { (EDIINT, X.400) }\end{array}$ & 3 & $13 \%$ \\
\hline $\begin{array}{l}\text { Physical medium } \\
\text { (CD, disc) }\end{array}$ & 2 & $8 \%$ \\
\hline
\end{tabular}

Figure 4. Invoice formats / standards and electronic channel for invoice presentation $(n=24)$

The survey suggests a correlation between the industry and the preference for certain electronic channels and invoice formats. For example, the retail, consumer goods and automotive industries are traditional EDI users, which is also reflected in their EBPP strategy. A recent survey by Thonemann \& Behrenbeck \& Küpper \& Magnus (2005) found that in the retail industry, 93\% of companies use EDI and $49 \%$ of all invoices are in the INVOIC format. Of the companies interviewed in the chemical industry, $65 \%$ use the ChemXML standard and over $80 \%$ are Elemica users. The conclusion drawn about the EBPP model is also reflected in the electronic integration alternatives: companies must adopt their EBPP strategy to the specific preferences of their customer base. In the chemical industry, this implies dealing with heterogeneous processes and IT infrastructure.

\subsection{The challenges of implementing and using EBPP}

The survey underlines the fact that the main challenges and problems involved in implementing or using EBPP are not related to the technical solutions. Concerns such as the technical integration with existing ERP systems, security issues or missing functionality of consolidators' solutions only play a minor role. The five main challenges of implementing and using EBPP are depicted in Figure 5. The real concerns are associated with business partners, processes and legislation. More than $90 \%$ of the companies claim that their business partners (mostly suppliers) are either not willing to use EBPP or not prepared for it. This is partly due to a resistance to change on the part of the employees and the organisation. Gamble (2001, p. 36) already drew attention to this hurdle in 2001: "Countless clerks at billers and payers have been using paper-based systems all their lives. Many feel threatened by systems changes, and the arguments for EBPP's efficiencies rarely penetrate upward to senior executives.” Especially for smaller businesses, the already outlined variety of implementation options and the costs involved represent a major obstacle. This was reflected by the experience of some interview partners who opted for the consolidator model and mentioned that their implementations are operational with only a handful of pilot partners so far. However, to achieve high benefits and justify the investment in the EBPP infrastructure, a substantial deployment within the company as well as within the industry is essential.

$80 \%$ of the interviewees considered the divergent legislation across Europe and its implementation in IT systems to be a significant challenge. The EU directive 2001/115 was intended to simplify and harmonise VAT regulations for electronic and paper invoices across the member states. Although all EU countries have transposed the Directive into national law as of January 2004 at the latest, actual practice still varies from country to country (Tanner et al. 2004). This "disharmonisation" of national legislations concerns the type of electronic signature required for proving the authenticity and integrity of e-invoices as well as archiving requirements (e.g. period and location) for electronic invoices and fiscal procedures. As an example, Germany considers an advanced electronic signature with a qualified certificate issued by a natural person as mandatory, whereas France and the Netherlands require an advanced electronic signature, and the Scandinavian countries Denmark and Finland accept all types of electronic invoices (European Commission 2005). Andreef \& Binmoeller \& Boboch \& 
Cerda \& Chakravorti \& Ciesielski \& Green (2001) describe similar experiences in the U.S. where it is unclear which state or country laws control Internet relationships (e.g. consumer protection laws).

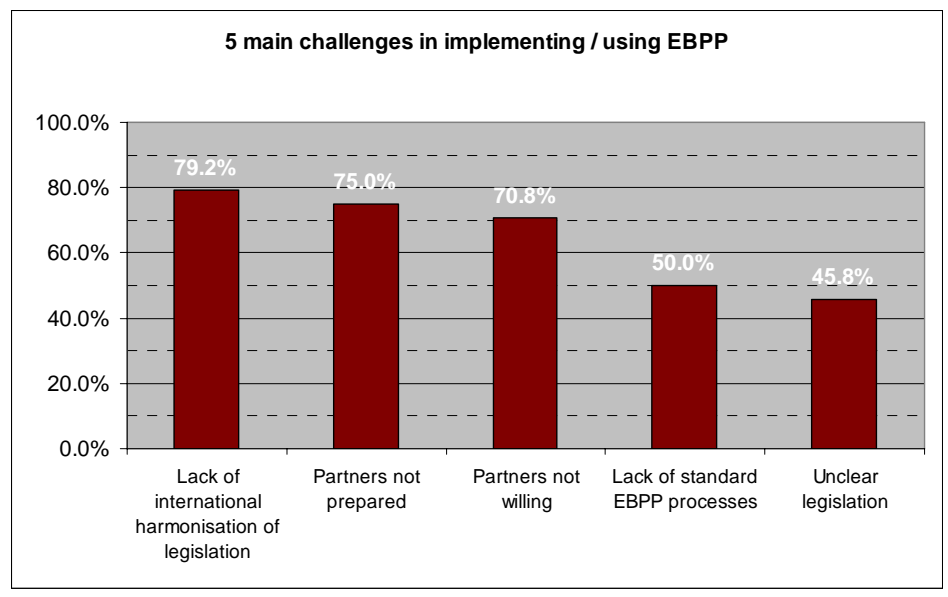

Figure 5. $\quad$ Five main challenges when implementing or using $\operatorname{EBPP}(n=24)$

Standardisation of invoice formats and of commonly accepted EBPP processes constitutes a hurdle for half of the companies interviewed. In the view of the interviewees, there is no lack of standardisation, but rather an abundance of concurring "standards" for electronic invoices: EDI or XML-based standards have been customised to the specific industry (e.g. EDIWheel in the tyre industry, ChemXML in the chemical industry) or region (see Section 2.2), while there are also many bilateral agreements between large business partners. These "barriers to EBPP" have already been mentioned by Andreef et al. (2001, p. 13) as "a lack of universal message standards", "different formats for the exchange of presentment data" and "the multitude of models, payment options and providers". Interestingly, cost-related issues, such as the difficulty of justifying the ROI of EBPP (21\%) or high implementation or operating costs (33\%), do not seem to be seen as relevant challenges by the interview partners.

\section{CONCLUSIONS}

The high response rate to the survey indicates that EBPP is a topical and controversial subject in the business-to-business area. Although nearly all companies were engaged in EBPP activities in some form or another, the survey indicates that penetration of electronic invoices is still marginal and the critical mass has not yet been reached. It reveals the discrepancy between the advantages of electronic, as compared to paper-based invoicing and the actual EBPP dissemination. Since various EBPP models, electronic channels and invoice formats are currently in use with no clear market trends, companies investing in EBPP implementations currently face the risk of the wrong adoption typical of markets in which network externalities exist. The following section discusses the evolution of EBPP and possibilities to achieve positive network externalities.

\subsection{Stages of EBPP implementations}

Companies started implementing EBPP solutions in the late 1990s using Internet-based technologies and services. However, transferring electronic invoices is not in fact a phenomenon of the Internet hype years. With the use of EDI technologies, electronic business documents, including invoices, have been transmitted by enterprises for 20 years and more.

The companies interviewed have been analysed with regard to the EBPP models, electronic channels and data formats they use, and three stages of EBPP implementation have been derived. Some 
companies could have been assigned to more than one stage since they currently complement their EDI-based models with Internet-based EBPP models for addressing smaller partners. Figure 7 displays the survey results according to the identified EBPP stages and Table 2 summarises their characteristics:

\begin{tabular}{|c|c|c|c|c|c|c|}
\hline \multirow[t]{2}{*}{ Phase } & \multirow{2}{*}{$\begin{array}{c}\text { Starting } \\
\text { year }\end{array}$} & \multirow{2}{*}{$\begin{array}{l}\text { Companies } \\
\text { in survey }\end{array}$} & \multicolumn{3}{|c|}{ Implementation characteristics } & \multirow{2}{*}{$\begin{array}{l}\text { Electronic } \\
\text { invoice rate }\end{array}$} \\
\hline & & & Model & Electronic channel & Format & \\
\hline EDI phase & 1980 & 4 & Direct & $\begin{array}{l}\text { Machine-to-machine } \\
\text { (EDI) }\end{array}$ & EDIFACT & $\begin{array}{l}\text { Moderate } \\
(\sim 30 \%)\end{array}$ \\
\hline Internet phase & 1998 & 12 & Direct & Portals, e-mail & PDF, XML & Low $(\sim 20 \%)$ \\
\hline $\begin{array}{l}\text { Consolidator } \\
\text { phase }\end{array}$ & 2002 & 8 & $\begin{array}{l}\text { Consoli- } \\
\text { dator }\end{array}$ & $\begin{array}{l}\text { Machine-to-machine } \\
\text { (Consolidator) }\end{array}$ & PDF, XML & $\begin{array}{l}\text { Very low / } \\
\text { pilots }(<10 \%)\end{array}$ \\
\hline
\end{tabular}

\section{Table 2. $\quad$ EBPP implementation stages}

The first phase ("EDI phase") already commenced in the 1980s and is characterised by EDI-based einvoicing using a direct model. The companies assigned to this phase process a relatively high percentage of electronic invoices compared to paper-based invoices.

In the late 1990s, companies started to implement the direct model using typical Internet channels like portals and e-mails to deliver and receive PDF and XML documents ("Internet phase"). The percentage of electronic invoices is still rather low, but some companies are quickly catching up.
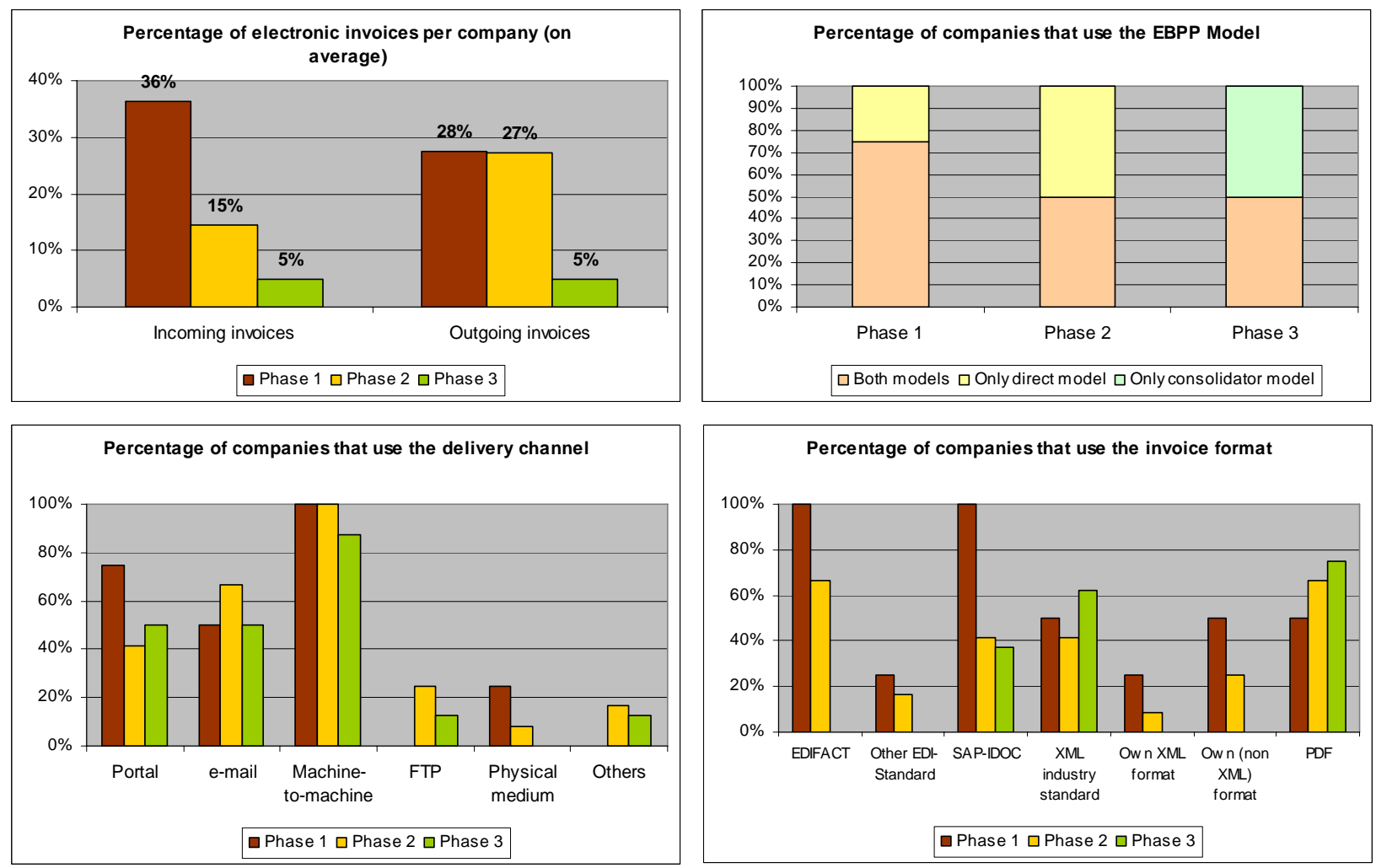

Figure 6. $\quad$ Characteristics of the three EBPP phases $(n=24)$

The last phase ("consolidator phase") started about three years ago, when companies increased ebusiness investments after the economy recovered from the bursting of the Internet bubble (Thayer 2002). Other drivers were the establishment of consolidators and the creation of supporting legal conditions (e.g. in the EU). This phase still reveals certain characteristics of the Internet-phase, such as the prevalence of portals and e-mails as well as XML and PDF documents. Companies have just 
started using consolidators and most have only pilots in place, so the amount of electronically delivered invoices remains very low (less than 10\%).

This analysis reveals a profusion of models and standards currently being used for EBPP. The different stages can be considered different "networks" which are not necessarily fully compatible with one another other. Switching costs explain the existence of EDI-based electronic invoicing, although Internet-based electronic invoicing offers various advantages with regard to implementation costs and availability to small and medium-sized partners.

\subsection{Hub-to-hub connections are vital for the future of EBPP}

The survey reveals that the dissemination of consolidators is dependent on the industry and/or the country. Industry platforms complement the existing EBPP consolidators and will play an important role in the dissemination of EBPP. Today, companies have to link up with more than one consolidator in order to cover the different regions and industries they serve. This implies fixed costs for setting up connections with consolidators and overhead necessary for reconciling various consolidator and business partner connections. It is not realistic to believe that in the future, only a few "generic" consolidators will survive and that heterogeneity will disappear. Instead, there is a high probability that country or industry-specific requirements remain which only specialised service providers can fulfil. In addition, companies using a consolidator model face a certain risk that the consolidator might not be able to reach the critical mass due to "excess inertia". Therefore, any company connected to it risks having to bear opportunity and replacement costs if the consolidator were to go bankrupt.

As a result, hub-to-hub connections are vital for the future of EBPP. Consolidators or industry platforms should establish connections with other consolidators and transfer invoice and payment data from one to another. This would increase the number of many-to-many-relationships, since companies would only need to connect to their preferred consolidator, which then transfers the data to their business partners, provided that they are connected to any other consolidator. These hub-to-hub connections already exist in the chemical industry for other business processes, e.g. order fulfilment: Elemica links to industry hubs in logistics, plastics, rubber (Thayer 2002) and ChemConnect links to ForestExpress (Thayer 2003) and GXS (ChemConnect 2005)).

\section{References}

Alt, R. and Zbornik, S. (2002). Integrierte Geschäftsabwicklung mit Electronic Bill Presentment and Payment. In E-Commerce: Netze, Märkte, Technologien, Proceedings zur Teilkonferenz der Multikonferenz Wirtschaftsinformatik 2002 (Weinhardt, C. and Holtmann, C. Ed.), 183-201, Physica, Heidelberg.

Andreef, A., Binmoeller, L.C., Boboch, E.M., Cerda, O., Chakravorti, S., Ciesielski, T. and Green, E. (2001). Electronic Bill Presentment and Payment - Is it Just a Click Away? Economic Perspectives, 25 (4), 2-16.

Buxmann, P., Wüstner, E. and Kunze, S. (2005). Wird XML/EDI traditionelles EDI ablösen? - Eine Analyse auf der Basis von Netzeffekten und einer empirischen Untersuchung. Wirtschaftsinformatik, 47 (6),

ChemConnect (2005). Hub-to-Hub. http://www.chemconnect.com/hub.html, visited 15-11-2005.

Dickerson, N., Raby, A., Sittinger, B. and Stewart, R. (2004). A Survey of Online Billing andPayment. Dept. Computer Science, University of Maryland, Baltimore County, Hilltop Circle.

Eicker, S. and Schwichtenberg, H. (2002). Bits and Bytes statt Papier. Essener Unikate, (18), 20-31.

Epper-Hoffmann, K. (2001). EBPP Fans Cling to Their Dream. Bank Technology News, (November), 23-26.

European Commission (2005). VAT in the European Community. http://europa.eu.int/comm/taxation_customs/taxation/vat/traders/vat_community/index en.ht

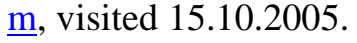


Fairchild, A.M. (2002). Value Positions for Financial Institutions in Electronic Bill Presentment and Payment (EBPP). In Proceedings of the 36th Hawaii International Conference on System Sciences (HICSS'03) (Sprague, R. Ed.), p. 196, Los Alamitos, CA.

Fairchild, A.M. (2004). Using Electronic Invoicing to Manage Cash Forecasting and Working Capital in the Financial Supply Chain. In Proceedings of the European Conference on Information Systems (ECIS) (Leino, T., et al. Ed.), Turku.

Frech, S., Egle, U. and Myrach, T. (2005). EBPP in der Schweiz: Eine qualitativ emprirische Untersuchung. Universität Bern, Bern.

Gamble, R. (2001). Battle of the Bills (EBPP). Treasury \& Risk Management, (July/August), 33-40.

Gowrisankaran, G. and Stavins, J. (2004). Network externalities and technology adoption: lessons from electronic payments. RAND Journal of Economics, 35 (2), 260-276.

Horan, T.F. (1998). Electronic Bill Presentment and Payment: The New 'Killer App' in the U.S. ECommerce Market. SIR Consulting, Menlo Park, CA.

Katz, M.L. and Shapiro, L. (1985). Network Externalities, Competition, and Compatibility. American Economic Review, 75 (3), 424-440.

NACHA (2000). Electronic Bill Presentment and Payment (EBPP) Business Practices. Council for Electronic Billing and Payment, Draft for Comment of Version 2.1. 09.05.2000, Herndon, VA.

NACHA (2001). Business-to-Business EIPP: Presentment Models and Payment Options; Part 1: Presentment Models. Council for Electronic Billing and Payment, Herndon, VA.

PayStream Advisors (2002). The Acceleration of Treasury Technology. PayStream Advisors, Summer 2002, Charlotte, NC.

Pfaff, D., Skiera, B. and Weiss, J. (2004a). Financial Supply Chain Management. Galileo Press, Bonn.

Pfaff, D., Skiera, B. and Weitzel, T. (2004b). Financial-Chain-Management - Ein generisches Modell zur Identifikation von Verbesserungspotenzialen. Wirtschaftsinformatik, 46 (2), 107-117.

Segev, A. and Gebauer, J. (2000). The Market for Internet-based Procurement Systems. Fisher Center for Information Technology and Marketplace Transformation, Haas School of Business, University of California, 99-WP1040; Part IV. Berkeley.

Skiera, B., König, W., Gensler, S., Weitzel, T., Beimborn, D., Blumenberg, S., Franke, J. and Pfaff, D. (2004). Financial Chain Management - Prozessanalyse, Effizienzpotentiale und Outsourcing. Books on Demand, Norderstedt.

Stabell, C.B. and Fjeldstad, O.D. (1998). Configuring Value for Competitive advantage: On Chains, Shops, and Networks. Strategic Management Journal, 19 (5), 413-437.

Tanner, C. and Koch, B. (2004). Die elektronische Rechnungsabwicklung in der Schweiz (EBPP). In E-Business mit betriebswirtschaftlicher Standardssoftware (Schubert, P., et al. Ed.), 157-168, Hanser, München.

Tanner, C. and Wölfle, R. (2005). Elektronische Rechnungsstellung zwischen Unternehmen. Fachhochschule beider Basel Nordwestschweiz, Institut für angewandte Betriebsökonomie, Basel.

Thayer, A.M. (2002). E-CONSOLIDATION - Shakeout in trading sites and network hubs brings needed clarity to chemical e-commerce. CENEAR, 80 (8), 13-17.

Thayer, A.M. (2003). E-Business. CENEAR, 81 (15), 21.

Thonemann, U., Behrenbeck, K., Küpper, J. and Magnus, K.-H. (2005). Supply Chain Excellence im Handel - Trends, Erfolgsfaktoren und Best-Practice-Beispiele. Gabler, Wiesbaden.

UN Economic Commission for Europe (2001). UN/EDIFACT Invoice Message. http://www.unece.org/trade/untdid/d01b/trmd/invoic_c.htm, visited 15.11.2005.

Varian, H.R., Farell, J. and Shapiro, C. (2004). The Economics of Information Technology - An Introduction. Cambridge University Press,

Weitzel, T. and König, W. (2003). Netzeffekte im E-Business. In Proceedings of the Internationale Tagung Wirtschaftsinformatik Ed.), 1-18, Dresden.

Young, D. (2000). EBPP 2000. Wireless Review, (December), 24-30. 